\title{
Dysplastic Gangliocytoma: A Rare Example of Cerebellar Tumor with An Evident Genetic Profile (Cowden Syndrome)
}

\author{
Javier Ortiz Rodríguez-Parets ${ }^{1,2^{*}}{ }^{(0)}$, Luis Miguel Chinchilla Tábora ${ }^{1,2}$, Enrique Montero Mateos ${ }^{1}$, \\ Elisa Muñoz Torres², María Dolores Ludeña de la Cruz ${ }^{1,2}$ \\ ${ }^{1}$ Department of Pathology, University Hospital of Salamanca (Spain), Salamanca, Spain \\ ${ }^{2}$ Department of Cell Biology and Pathology, The Medical School University of Salamanca, Salamanca, Spain \\ Email:*jortiz@usal.es
}

How to cite this paper: Ortiz, J., Chinchilla, L.M., Montero, E., Muñoz, E. and Ludeña, M.D. (2021) Dysplastic Gangliocytoma: A Rare Example of Cerebellar Tumor with An Evident Genetic Profile (Cowden Syndrome). Open Journal of Pathology, 11, 33-37.

https://doi.org/10.4236/ojpathology.2021.1 $\underline{12004}$

Received: November 28, 2020

Accepted: April 23, 2021

Published: April 26, 2021

Copyright $\odot 2021$ by author(s) and Scientific Research Publishing Inc. This work is licensed under the Creative Commons Attribution International License (CC BY 4.0).

http://creativecommons.org/licenses/by/4.0/

\begin{abstract}
Objective: To describe the histological and immunohistochemical findings observed when studying a dysplastic cerebellar gangliocytoma observed in a 33-year-old man with a history of Thyroid Cancer. Material and Methods: Radiological images (MRI) and histological and immunohistochemical preparations obtained from the cerebellar tissue were received in our laboratory. Results: A neoplasm constituted by aberrant-looking mature neurons was observed that showed negativity for the immunohistochemical markers of the PTEN protein, expression of the activity of the PTEN gene. Conclusions: Verify the diagnosis of a rare entity, clearly related in scientific publications with Cowden's Syndrome.
\end{abstract}

\section{Keywords}

Dysplastic Gangliocytoma, Immunohistochemistry, Cowden Syndrome

\section{Introduction}

The current standard of hospital care requires pathologists to give increasingly accurate diagnoses providing information on not only the nature of the lesion (tumoral or reactive inflammatory), its histological lineage and its prognosis, but also on clues about its etiopathogenesis.

This especially true for lesions of genetic origin that are susceptible to hereditary transmission, in which it is necessary to monitor and advises both the patient and his or her relatives.

In these situations, immunohistochemistry and molecular biology techniques 
are indispensable tools employed by pathologists to detect genetic mutations of great interest in clinical.

The abovementioned factors can be considered in the case reported herein of a very rare cerebellar tumor closely associated with a mutation of the PTEN gene.

\section{Clinical Case}

A 33-year-old man, without familiar history of interest, reported two years earlier a thyroid papillary carcinoma with follicular pattern, treated with hemithyroidectomy. The patient presented to our hospital with neurological symptoms (headache, gait disturbances, ataxia and dysmetria) in recent weeks, suggestive of a cerebellar hemispheric origin.

Radiological studies (MRI) confirmed the existence of an expansive lesion 4.8 $\mathrm{cm}$ in maximum diameter in the left cerebellar hemisphere that was causing displacement and distortion of the fourth ventricle (Figure 1). With suspicion of metastasis, the patient underwent surgery, and the entire resected lesion was sent to our laboratory, where the histological study was performed.

Microscopic examination revealed abnormal proliferation of large cells with a neuronal habit and a large amount of cytoplasm, some of which were optically empty (Figure 2(a)). Positive immunohistochemistry (enolase, synaptophysin

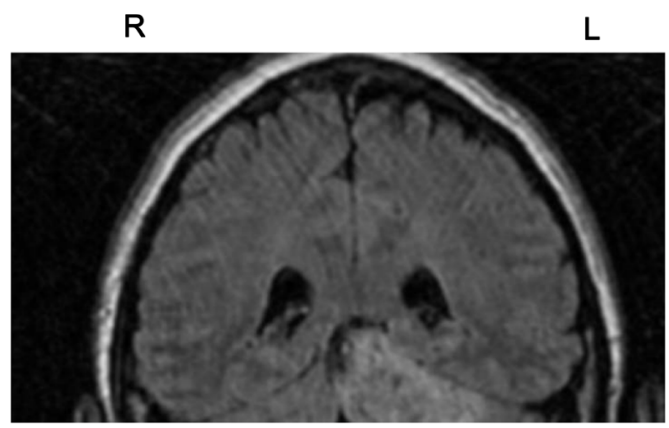

Figure 1. MRI (coronal fast fluid-attenuated inversion recovery (FLAIR) inversion recovery fast spin echo sequence (FLAIR irFSES)): Space-occupying lesion located in the left cerebellar hemisphere.

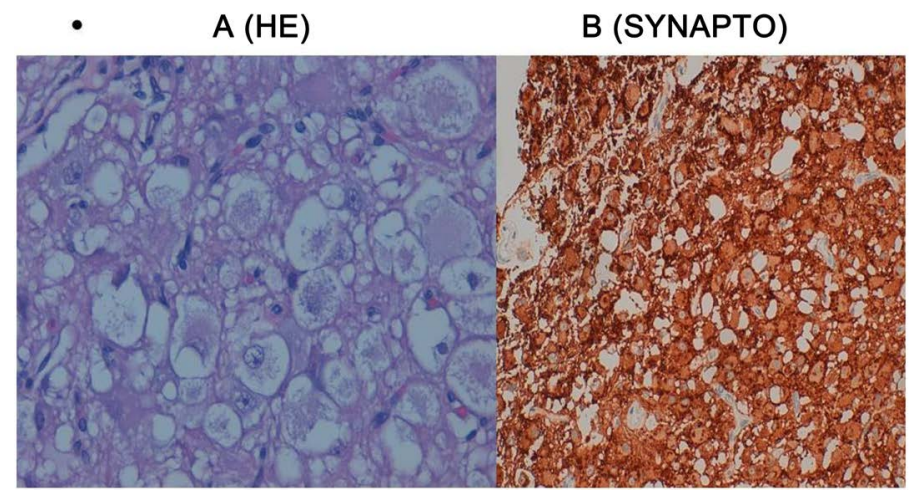

Figure 2. (a) Dysplastic gangliocytoma: Atypical large neuronal cells, some of which were optically empty (HE $\times 400$ ); (b) Dysplastic gangliocytoma (Immunohistochemistry): Strong positivity of aberrant cells for synaptophysin (Synaptophisin $\times 200$ ). 
and neurofilaments) confirmed the neuronal lineage of these cells (Figure 2(b)). Similarly, immunohistochemical markers showed low tumor proliferative activity (Ki67 less than 1\%) and negativity for the PTEN protein, encoded by the PTEN gene, both in tumor cells and histologically normal cerebellum (Figure 3(a) and Figure 3(b)). On the contrary, in tissue lacking the mutation, used as a control, the positivity of this marker is observed (Figure 4).

Based on these findings, our diagnosis was dysplastic gangliocytoma of the cerebellum (Lhermitte-Duclos disease).

\section{Discussion}

Mutation of the tumor suppressor gene PTEN, a gene located on the long arm of chromosome 10 (10q23), is the genetic alteration that characterizes Cowden syndrome, also called multiple hamartoma syndrome [1] [2] [3].

This hereditary syndrome has an autosomal dominant pattern and is characterized by the development of multiple benign and malignant neoplasms in the thyroid, breast, endometrium, colon, and kidney [4] [5]. Despite the great diversity of neoplasms that can accompany this syndrome, there are two entities, both benign in nature, whose presence is practically pathognomonic. The first one is multiple trichilemmomas [6] [7], cutaneous adnexal neoplasms of pilar origin

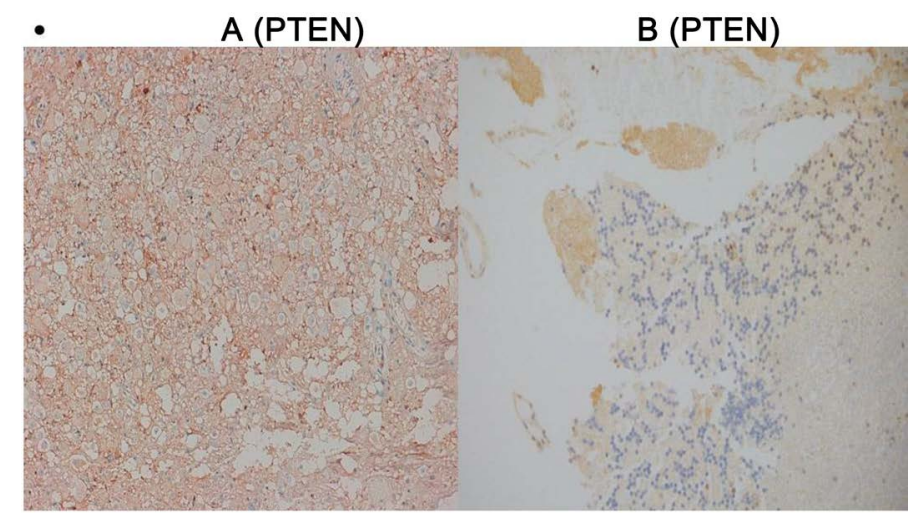

Figure 3. (a) Immunohistochemistry Negativity of tumor cells for PTEN (PTEN $\times 200$ ); (b) Immunohistochemistry Negativity of normal tissue for PTEN $($ PTEN $\times 200)$.

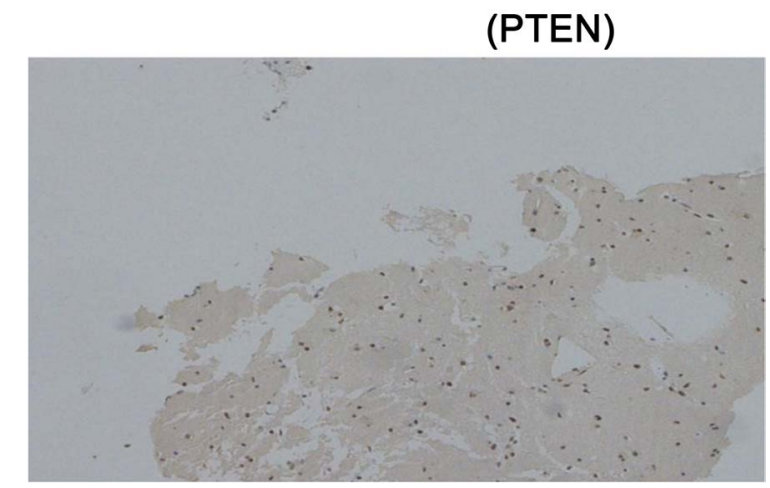

Figure 4. Immunohistochemistry. Normal brain tissue used as PTEN control Nuclear positivity of cells for this marker (Immunohistochemistry PTEN $\times 100$ ). 
with a predominantly facial location. The second entity is dysplastic gangliocytoma. This rare tumor, described in 1920 by J. J. Lhermitte and P. Duclos [8], is characterized by its slow growth, its typical location (cerebellar hemispheres) and its peculiar histological appearance (aberrant-looking mature neurons). Due to its histogenesis and controversial nature, dysplastic gangliocytoma is currently believed to derive from cerebellar granular cells and to be fundamentally hamartomatous in nature [9] [10] [11].

Dysplastic gangliocytoma is considered a benign process and is included by the WHO within the grade I neoplasms group [12]. Cases of tumor recurrence have been described, but they may be secondary to incomplete resection of the lesion [13].

Our case presented dysplastic gangliocytoma, which clinically and histologically coincided with the examples described by other researchers. The clinical history of the patient (thyroid cancer) and his negativity for the PTEN immunohistochemical marker support our diagnosis, as does his favorable progression. The patient who underwent periodic check-ups, five years after his surgical intervention, does not present recurrence of his cerebellar and thyroid neoplasms, having developed, on the contrary, facial lesions compatible with trichilemmomas (we do not have histological images).

To conclude, we would like to highlight once again the importance of histopathology in the daily routine as an indispensable tool for clinicians for the provision of good hospital care.

\section{Conflicts of Interest}

The authors declare no conflicts of interest regarding the publication of this paper.

\section{References}

[1] Nosé, V. (2016) Genodermatosis Affecting the Skin and Mucosa of the Head and Neck: Clinicopathologic, Genetic, and Molecular Aspect-PTEN-Hamartoma Tumor Syndrome/Cowden Syndrome. Head and Neck Pathology, 10, 131-138. https://doi.org/10.1007/s12105-016-0708-7

[2] Monga, E., Gupta, P.K., Munshi, A. and Agarwal, S. (2014) Multiple Hamartoma Syndrome: Clinicoradiological Evaluation and Histopathological Correlation with Brief Review of Literature. Indian Journal of Dermatology, 59, 598-601. https://doi.org/10.4103/0019-5154.143535

[3] Porto, A.C.S., Roider, E. and Ruzicka, T. (2013) Cowden Syndrome: Report of a Case and Brief Review of Literature. The Journal Brazilian Annals of Dermatology, 88, 52-55. https://doi.org/10.1590/abd1806-4841.20132578

[4] Wang, W.-C., Hou, T.-C., Kuo, C.-Y. and Lai, Y.-C. (2020) Hints from a Female Patient with Breast Cancer Who Later Presented with Cowden Syndrome. Journal of Breast Cancer, 23, 430-437. https://doi.org/10.4048/jbc.2020.23.e25

[5] Shuch, B., Ricketts, C.J., Vocke, C.D., Komiya, T., Middelton, L.A., et al. (2013) Germline PTEN Mutation Cowden Syndrome: An Under-Appreciated Form of Hereditary Kidney Cancer, Journal of Urology, 190, 1990-1998. 
https://doi.org/10.1016/j.juro.2013.06.012

[6] Brownstein, M.H., Mehregan, A.H., Bikowski, J.B., Lupulescu, A. and Patterson, J.C. (1979) Patterson The dermatopathology of Cowden's Syndrome. British Journal of Dermatology, 100, 667-673. https://doi.org/10.1111/j.1365-2133.1979.tb08070.x

[7] Gosein, M.A., Narinesingh, D., Nixon, C.A.C., Goli, S.R., Maharaj, P. and Sinanan, A. (2016) Multi-Organ Benign and Malignant Tumors: Recognizing Cowden Syndrome: A Case Report and Review of the Literature. BMC Research Notes, 9, Article No. 388. https://doi.org/10.1186/s13104-016-2195-Z

[8] Lhermitte, J. and Duclos, P. (1920) Sur un ganglioneurome diffuse du cortex du cervelet. Bulletin de I Association Francaise pour l'etude du Cancer (Paris), 9, 99-107.

[9] Cheng, C.-S., Ou, C.-H., Chen, J.-S., Lui, C.-C. and Yeh, L.-R. (2019) Lhermitte-Duclos Disease: A Case Report with Radiologic-Pathologic Correlation. Radiology Case Reports, 14, 734-739. https://doi.org/10.1016/j.radcr.2019.03.020

[10] Biswas, S.N., Chakraborty, P.P. and Patra, S. (2016) Lhermitte-Duclos Disease. BMJ Case Reports, 2016, bcr2015214235. https://doi.org/10.1136/bcr-2015-214235

[11] Nowak, D.A. and Trost, H.A. (2002) Lhermitte-Duclos Disease (Dysplastic Cerebellar Gangliocytoma): A Malformation, Hamartoma or Neoplasm? Acta Neurologica Scandinavica, 105, 137-145. https://doi.org/10.1034/j.1600-0404.2002.1r127.x

[12] Eberhart, C.G., Wiestler, O.D. and Eng, C. (2016) Dysplastic Cerebellar Gangliocytoma (Lhermitte-Duclos Disease). In: Louis, D.N., Otmar, H., Wiesler, O.D. and Cavenee, W.K., Ed., Who Classification of Tumors of the Central Nervous System, International Agence for Research on Cancer Lyon, Lyon, 142-146.

[13] Ajithkumar, T., Imbulgoda, N., Rees, E., Harris, F., Horan, G., Burke, A., et al. (2019) Uncommon Low-Grade Brain Tumors. Neuro-Oncology, 21, 151-166. https://doi.org/10.1093/neuonc/noy151 